\title{
The Effect of Admission Year and Effort-Reward Imbalance Model on Engagement
}

\author{
Jung Eun Hwang ${ }^{1}$, Na Jin $\mathrm{Kim}^{2}$ \& Su Young Kim ${ }^{1,3}$ \\ ${ }^{1}$ Department of Pathology, College of Medicine, The Catholic University of Korea, Seoul, Republic of Korea \\ ${ }^{2}$ Master Center for Medical Education Support, College of Medicine, The Catholic University of Korea, Seoul, \\ Republic of Korea \\ ${ }^{3}$ Department of Biomedicine and Health Sciences, The Catholic University of Korea, Seoul, Republic of Korea \\ Correspondence: Su Young Kim, Department of Pathology, College of Medicine, The Catholic University of \\ Korea, 222 Banpo-daero, Seocho-gu, Seoul 06591, Republic of Korea. Tel: 82-2-2258-7315. E-mail: \\ suyoung.dr@gmail.com
}

Received: October 22, 2019

Accepted: November 19, 2019

Online Published: December 9, 2019

doi:10.20849/jed.v3i3.662

URL: https://doi.org/10.20849/jed.v3i3.662

Part of this research was presented for a short communication in AMEE 2019.

\begin{abstract}
Engagement has not been widely studied in the field of medical education. The purpose of this study was to determine the relationship between admission year and engagement, assuming that characteristics of admission cohorts might be different depending on year. Association between effort-reward imbalance (ERI) model and engagement was also reinvestigated. Data were collected from 164 students in The Catholic University of Korea, College of Medicine. Ninety-nine (18.97\%) students in 2017 and 65 (12.38\%) students in 2018 answered an online questionnaire measuring demographic variables, ERI, over-commitment (OC), negative affect, and engagement. Participants' admission years were determined based on years in school they responded. Affiliation and year in school were removed because of their high correlation with admission year. Categorical regression analysis was performed. Admission year, binary ERI, and OC were significant explanatory variables in this categorical regression model $\left(\mathrm{R}^{2}=.312\right.$, Adjusted $\left.\mathrm{R}^{2}=.255, \mathrm{~F}=5.444, \mathrm{p}=.000\right)$. Admission year, binary ERI, and OC accounted for $13.4 \%, 27.9 \%$, and $9.4 \%$ of the importance in this model, respectively. Quantification plots for admission year and binary ERI showed that engagement was the highest in 2018 admission cohort but the lowest in 2013 admission cohort; being reciprocally rewarded for efforts was associated with higher scores of engagement. A certain admission cohort can be more engaged or less engaged in learning. This study also confirms that receiving proper rewards for efforts could be related to increase in engagement.
\end{abstract}

Keywords: undergraduate medical education, effort-reward imbalance, admission year, engagement

\section{Introduction}

\subsection{Engagement of Medical Students}

Engagement, a positive and rewarding psychological state in a learning process (Liu et al., 2018), is known as a salient factor in medical students' self-directed and effective learning (Richards, Sweet, \& Billett, 2013). While engagement is known to be related to academic achievement (Gómez et al., 2015; Hansen, D'Urso, \& Fracchia, 2016) and personal performance (Hansen et al., 2016), research on engagement in the field of medical education has not been widely conducted (Siyami, Akbari, \& Ayati, 2014).

Over the past decade, researchers in medical education have investigated engagement of medical students depending on teaching methods, personalities, psychological needs, and coping strategies. It has been reported that medical students' preferred teaching styles are significantly related to engagement (Siyami et al., 2014) and that high extroversion is associated with engagement (Hansen et al., 2016). In addition, it has been found that engagement has significant relationships with competence, autonomy, self-compassion, and mastery approach goals (Babenko, Mosewich, Abraham, \& Lai, 2018). For demographic variables, one study (Liu et al., 2018) has found no significant sex difference. However, two previous studies (Babenko et al., 2018; Siyami et al., 2014) 
have shown that engagement of female students is higher than that of male students. Also, students in lower year in school reported greater engagement than those in higher year in school (Babenko et al., 2018; Liu et al., 2018). Considering that demographic variables play a considerable role in elucidating positive psychological constructs (Singh, Junnarkar, \& Kaur, 2016), their relationship with engagement of medical students needs to be studied due to the lack of research.

\subsection{Admission Year and Engagement}

Thus, the objective of this study was to investigate the relationship between engagement and admission year. Most previous studies assumed that study variables did not differ significantly by admission year of medical students. However, some studies have revealed that levels of psychological variables and academic achievement can vary depending on medical students' admission cohorts. One study on new medical students (Nishiyama et al., 2016) have shown that the distribution of subjective well-being is significantly different by admission years. Their comprehensibility also showed difference by admission year at significance level of $p<.1$. Another study (Gupta, Nagpal, \& Dhaliwal, 2013) has reported that participants in certain admission year have significantly higher academic achievement than those in other admission years. Another study (Kaistha et al., 2013) has shown that psychiatric morbidity prevalence by admission year varies from $23.6 \%$ to $42 \%$, although the difference is not statistically significant. Because the difference across admission year was not the focus of their research, the authors just presented these results or interpreted admission year as year in school (Gupta et al., 2013; Kaistha et al., 2013; Nishiyama et al., 2016).

One of the reasons that research variables altered by admission year might be due to changes in admission processes. Previous studies have shown that non-cognitive characteristics (D. H. Kim et al., 2014) and academic achievement (S. H. Kim, Lee, Hur, \& Kim, 2013; Kraft, Lamina, Kluckner, Wild, \& Prodinger, 2013) of premedical or medical students are significantly different by admission type. Since medical schools' admission processes have changed a little bit from year to year, motivation or academic performance of students entering each year might be different. Therefore, we aimed to confirm whether admission year could be a factor when explaining students' engagement.

\subsection{Effort-Reward Imbalance Model and Engagement}

Another focus of our research was to reaffirm relationship between effort-reward imbalance (ERI) model and medical students' engagement. According to the ERI model (Siegrist, 1996; Siegrist et al., 2004), study-related stress occurs when students' effort is not reciprocally rewarded, that is, when there is an imbalance between effort and reward. It is also known that over-commitment (OC) tendency can strengthen the impact of this imbalance on stress. For medical students, ERI and OC have been reported to be significantly associated with poor health, anxiety, and depression (Hahn, Kropp, Kirschstein, Rucker, \& Muller-Hilke, 2017; Hilger-Kolb, Diehl, Herr, \& Loerbroks, 2018). Yet, the relationship between ERI and positive psychological indicators such as engagement has not been fully explored yet except a pilot study (Hwang, Kim, Kwon, \& Kim, 2019). Thus, in this study, we tried to reexamine whether ERI and OC had a significant association with engagement using our two years' data of premedical and medical students.

Our hypotheses about the admission year, ERI model, and engagement are summarized as follows:

Hypothesis 1. Engagement will differ significantly by admission year.

Hypothesis 2. ERI and OC will be significantly associated with engagement.

\section{Methods}

\subsection{Data Collection}

Data were collected from premedical and medical students. The Catholic University of Korea, College of Medicine offers a two-year premedical course and a four-year medical course. The medical course includes students in college of medicine and medical graduate school.

A web-based questionnaire of our learning management system was utilized from September $25^{\text {th }}$ to December $7^{\text {th }}$ in 2017 and from September $14^{\text {th }}$ to November $17^{\text {th }}$ in 2018 . A total of $99(18.97 \%)$ respondents in 2017 and $65(12.38 \%)$ respondents in 2018 completed the questionnaire. Among 164 cases, six cases were excluded due to insincere or insufficient responses. Thus, a total of 158 cases were selected as research samples. Characteristics of the study sample are summarized in Table 1. 
Table 1. Characteristics of study sample $(\mathrm{N}=158)$

\begin{tabular}{|c|c|c|c|}
\hline Nominal variable & Group & Frequency & y $\quad$ Percent $(\%)$ \\
\hline \multirow{2}{*}{ Gender } & a)(1) Male & 82 & 51.9 \\
\hline & (2) Female & 76 & 48.1 \\
\hline \multirow{3}{*}{ Affiliation } & a)(1) Premedical course & 39 & 24.7 \\
\hline & (2) College of medicine & 35 & 22.2 \\
\hline & (3) Medical graduate school & 84 & 53.2 \\
\hline \multirow{2}{*}{ Survey year } & a)(1) 2017 & 97 & 61.4 \\
\hline & (2) 2018 & 61 & 38.6 \\
\hline \multirow{6}{*}{ Year in school } & a) (1) Premed $1^{\text {st }}$ & 20 & 12.7 \\
\hline & (2) Premed $2^{\text {nd }}$ & 19 & 12.0 \\
\hline & (3) Med $1^{\text {st }}$ & 23 & 14.6 \\
\hline & (4) Med $2^{\text {nd }}$ & 35 & 22.2 \\
\hline & (5) Med $3^{\text {rd }}$ & 38 & 24.1 \\
\hline & (6) Med $4^{\text {th }}$ & 23 & 14.6 \\
\hline \multirow{7}{*}{ Admission year } & a)(1) 2018 & 12 & 7.6 \\
\hline & (2) 2017 & 17 & 10.8 \\
\hline & (3) 2016 & 20 & 12.7 \\
\hline & (4) 2015 & 26 & 16.5 \\
\hline & (5) 2014 & 33 & 20.9 \\
\hline & (6) 2013 & 33 & 20.9 \\
\hline & (7) 2012 & 17 & 10.8 \\
\hline \multirow{2}{*}{$\begin{array}{l}\text { Effort-reward } \\
\text { imbalance }\end{array}$} & a)(1) Effort $\leq$ Reward & 64 & 40.5 \\
\hline & (2) Effort > Reward & 94 & 59.5 \\
\hline Numeric variable & Standard c & Standard deviation & Possible range \\
\hline Age $(\mathrm{N}=157)$ & 24.05 & 3.551 & $18-36^{\text {b) }}$ \\
\hline Engagement & 14.353 & 14.353 & $0-102$ \\
\hline Effort & 11.73 & & $4-16$ \\
\hline Reward & 2.498 & & $4-16$ \\
\hline Over-commitment & 10.42 & & $5-20$ \\
\hline Negative affect & 23.18 & & $10-50$ \\
\hline
\end{tabular}

a) Values of nominal variables were coded as numbers

b) Actual range of age in this data

\subsection{Instruments}

\subsubsection{Engagement}

Engagement was assessed using Utrecht Work Engagement Scale of Students (Schaufeli, Martinez, Pinto, Salanova, \& Baker, 2002). The scale had 17 items. Examples are: "When I study, I feel like I am bursting with energy." (vigor), "I find my studies to be full of meaning and purpose." (dedication), and "When I am studying, I forget everything else around me." (absorption). Participants were on a 7-point Likert scale, ranging from 0 (never) to 6 (always). In a validation study of Korean college students (Roemer, 2016), Cronbach's alpha values of its three subscales ranged from .73 to .81 . Both three-factor and one-factor models were found to be acceptable. 


\subsubsection{Demographic Variables}

We obtained information on admission year as well as gender, age, affiliation, year in school, and survey year. As for admission year, most students in our college advanced to a next level together except for very few students who failed. Thus, participants' admission years were figured out using years in school they answered. To conduct a categorical regression analysis, we turned scores on nominal scales into consecutive integers that began with one (McCormick, Salcedo, Peck, \& Wheeler, 2017). Gender, affiliation, year in school, admission year, and survey year were coded in this way (Table 1).

\subsubsection{Effort-Reward Imbalance and Over-Commitment}

ERI and OC were measured with a short student version of ERI questionnaire (Wege, Li, Muth, Angerer, \& Siegrist, 2017). This version consisted of 14 items. Examples are: "I have constant time pressure due to a heavy study load." (effort), "I receive the respect I deserve from my supervisors / my fellow students." "Considering all my efforts and achievement, my job promotion prospects are adequate." (reward), and "Student work rarely lets me go; it is still on my mind when I go to bed." (OC). In a validation study (Wege et al., 2017), Cronbach alpha value for each subscale ranged from .65 to .79 . Since this version was not repeatedly validated in several studies, we added some items of short form (Siegrist, Wege, Puhlhofer, \& Wahrendorf, 2009) that were omitted from the ERI Questionnaire. Participants were evaluated on 4-point Likert scale ranging from 1 (strongly disagree) to 4 (strongly agree), with higher scores reflecting higher effort, reward, and OC.

ERI ratio was calculated with effort, reward, and correction factor as suggested by Siegrist et al. (Siegrist et al., 2004). To perform categorical regression analysis, data should not have negative numbers. They should be integers (McCormick et al., 2017). Therefore, ERI ratio was transformed into a binary variable. ERI ratio was coded as one if reward was equal to or greater than effort. It was coded as two if reward was less than effort (Table 1).

\subsubsection{Negative Affect}

Negative affect was a confounder (Feuerhahn, Kühnel, \& Kudielka, 2012; Preckel, Meinel, Kudielka, Haug, \& Fischer, 2007) in our model. Negative affect was assessed with Positive and Negative Affect Schedule (PANAS) (Watson, Clark, \& Tellegen, 1988). We only used ten items of PANAS to evaluate negative affect. Participants rated degree of mood they felt during last two or three weeks on a 5-point Likert scale ranging from 1 (very slightly or not at all) to 5 (extremely). In a scale validation study of the Korean version (Lee, Kim, \& Lee, 2003), Cronbach's alpha value for PANAS negative affect was .87 .

\subsection{Statistical Analysis}

First, explanatory factor analysis was performed to determine whether ERI questionnaire could be divided into effort, reward, and OC. Confirmatory factor analysis verified model fit of the three-factor model. Second, descriptive statistics of our data were calculated. We then computed Cronbach's alpha values of scales and Pearson's correlation coefficients between numeric variables (age, effort, reward, OC, negative affect, and engagement). For nominal variables (gender, affiliation, survey year, year in school, admission year, and binary ERI), differences in engagement groups by categories were tested. When engagement groups by categories in nominal variables satisfied normality tests, we performed parametric tests. If not, we performed non-parametric tests.

Finally, we conducted categorical regression analysis which expanded a regression model through quantifying categorical variables (McCormick et al., 2017). This analysis can transform scores of nominal or ordinal scales so that researchers can use these variables for linear regression (McCormick et al., 2017). For this, assumptions of multiple regression model and categorical regression model were checked. Outliers and influential observations were detected with residual scatter plots and Cook's distances. Normal probability plots, residual scatter plots, and Durbin-Watson statistics were used to examine normality, linearity, homoscedasticity, and independence of residuals. Tolerances and correlation coefficients were indicators of explanatory variables' multicollinearity. To confirm assumptions of regression, affiliation and year in school that showed correlations of greater than .9 with admission year were excluded from explanatory variables.

Categorical regression analysis produces three indices to interpret the relationship between explanatory variables and an outcome variable: correlation coefficients, beta coefficient, and importance values. An explanatory variable's importance value can be calculated by dividing the variable's relative importance by an $R^{2}$ value. Relative importance is produced by multiplying the variable's zero-order correlation coefficient and its beta coefficient (McCormick et al., 2017). We choose to use importance values to examine contributions of explanatory variables to engagement because an importance value considers a zero-order correlation coefficient, 
a beta coefficient, and an $\mathrm{R}^{2}$ value together in the value.

Additionally, we put affiliation in another model and year in school in the other model instead of putting admission year in order to compare these three variables' importance values in each model.

Data were processed with IBM SPSS Statistics 25. IBM SPSS Amos 25 was used only for confirmatory factor analysis. A value of $p<.05$ was considered statistically significant in all analyses. The study protocol (MC17QESI0046) was approved by the Institutional Review Board of The Catholic University of Korea, College of Medicine. All personal information was anonymized.

\section{Results}

Through explanatory factor analysis of ERI questionnaire, we excluded two items with commonality less than .4 and one item related to two factors. One item (about time pressure) in OC subscale was found to be associated with effort factor. Confirmatory factor analysis revealed that goodness-of-fit of the three-factor model was moderate $(\mathrm{RMSEA}=.087, \mathrm{TLI}=.836, \mathrm{CFI}=.870)$.

In Table 2, Pearson's correlation coefficient $(\mathrm{r})$ showed that age and $\mathrm{OC}$ were not significantly correlated with engagement. However, effort $(r=-.255)$, reward $(r=.440)$, and negative affect $(r=-.354)$ had significant correlations with engagement at $\mathrm{p}<.05$. Table 3 displayed differences of engagement groups by categories of nominal variables. Because engagement groups by categories in survey year, year in school, and binary ERI satisfied normality test, $\mathrm{t}$ or $\mathrm{F}$ test was carried out. Since engagement groups by categories in gender, affiliation, or admission year did not satisfy the normality test, Mann-Whitney U test or Kruskal-Wallis $\mathrm{H}$ test was performed. There was no significant difference in engagement groups except binary ERI $(t=4.456, p=.000)$.

Table 2. Pearson correlation coefficients between numeric variables and reliability ${ }^{\text {a) }}(\mathrm{N}=158)$

\begin{tabular}{lllllll}
\hline & 1 & 2 & 3 & 4 & 5 & 6 \\
\hline 1 Age & - & \multicolumn{7}{l}{} \\
\hline 2 Effort & .139 & $(.700)$ & & & & \\
\hline 3 Reward & .014 & $-.276^{*}$ & $(.800)$ & & & \\
\hline 4 Over-commitment & $.295^{*}$ & $.446^{*}$ & -.048 & $(.719)$ & & \\
\hline 5 Negative affect & .080 & $.485^{*}$ & $-.354^{*}$ & $.405^{*}$ & $(.924)$ & \\
\hline 6 Engagement & .076 & $-.255^{*}$ & $.440^{*}$ & .091 & $-.354^{*}$ & $(.921)$ \\
\hline
\end{tabular}

${ }^{\text {a) }}$ Cronbach's alphas are in parentheses.

${ }^{*} \mathrm{p}<.05$

Table 3. Differences of engagement groups by categories in nominal variables $(\mathrm{N}=158)$

\begin{tabular}{|c|c|c|c|c|}
\hline \multirow{2}{*}{ Variable } & & \multicolumn{3}{|l|}{ Engagement } \\
\hline & & Mean (SD) & Test statistic & p-value \\
\hline \multirow{2}{*}{ Gender } & Male & $56.38(15.798)$ & \multirow{2}{*}{$\mathrm{U}=3082.500$} & \multirow{2}{*}{.907} \\
\hline & Female & $56.96(12.708)$ & & \\
\hline \multirow{3}{*}{ Affiliation } & Premedical course & $57.18(14.011)$ & \multirow{3}{*}{$\mathrm{H}=.056$} & \multirow{3}{*}{.972} \\
\hline & College of medicine & $56.91(15.921)$ & & \\
\hline & Medical graduate school & $56.31(13.988)$ & & \\
\hline \multirow{2}{*}{ Survey year } & 2017 & $57.98(12.840)$ & \multirow{2}{*}{$\mathrm{t}=1.386$} & \multirow{2}{*}{.169} \\
\hline & 2018 & $54.56(16.369)$ & & \\
\hline \multirow{4}{*}{ Year in school } & Premed $1^{\text {st }}$ & $55.35(16.608)$ & \multirow{4}{*}{$\mathrm{F}=.237$} & \multirow{4}{*}{.946} \\
\hline & Premed $2^{\text {nd }}$ & $59.11(10.754)$ & & \\
\hline & Med $1^{\text {st }}$ & $57.74(13.619)$ & & \\
\hline & $\operatorname{Med} 2^{\text {nd }}$ & $57.06(15.941)$ & & \\
\hline
\end{tabular}




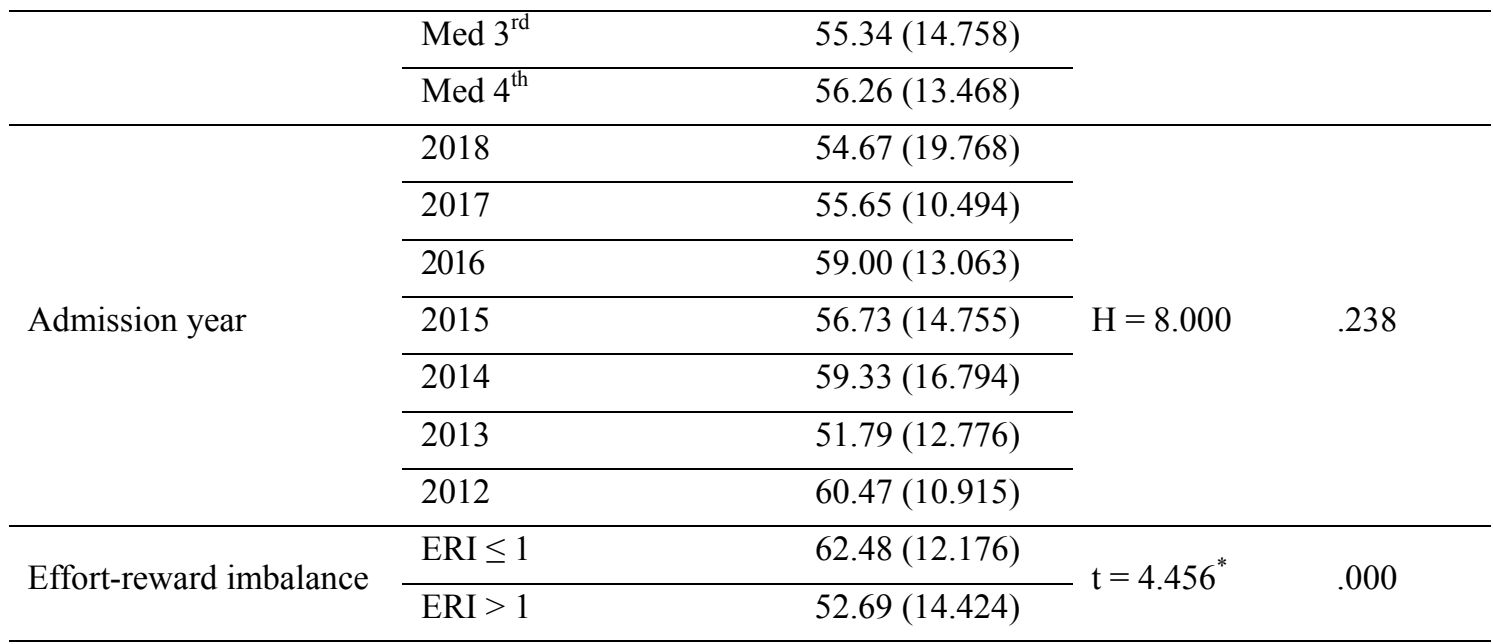

SD: Standard deviation

U: Mann-Whitney U test

H: Kruskal-Wallis H test

$\mathrm{t}$ : $\mathrm{t}$ test

F: F test

\subsection{Results of Categorical Regression Analysis}

The total number of cases used for analysis was 157 . One case without age was excluded. Results of categorical regression analysis are presented in Table 4. Explanatory variables accounted for $31.2 \%$ of variance of engagement $\left(\mathrm{R}^{2}=.312\right)$. After adjusting for the number of explanatory variables relative to sample size, adjusted coefficient of determination was .255 . There were significant relationships between engagement and explanatory variables $(\mathrm{F}=5.444, \mathrm{p}=.000)$, including admission year $(\mathrm{Beta}=.290, \mathrm{p}=.000)$, binary ERI (Beta $=.254, \mathrm{p}$ $=.001)$, OC $($ Beta $=.339, \mathrm{p}=.000)$, and negative affect $($ Beta $=-.363, \mathrm{p}=.000)$. Hypotheses 1 and 2 were fully supported. Negative affect, OC, and engagement were defined as numeric variables in our model. Thus, relationships between these two explanatory variables and engagement were interpreted as linear regression. Increase in $\mathrm{OC}$ was significantly related to increase in engagement. In contrast, increase in negative affect was significantly associated with decrease in engagement. OC and negative affect explained $9.4 \%$ and $41.2 \%$ of the importance in this categorical regression model, respectively.

Table 4. Result of categorical regression analysis of engagement $(\mathrm{N}=157)$

\begin{tabular}{lllll}
\hline \multirow{2}{*}{ Variable } & Engagement & & \\
\cline { 2 - 5 } & Beta coefficient $^{\mathrm{a}}$ & $\mathrm{p}$-value & Importance & Tolerance \\
\hline Gender & .056 & .328 & -.003 & .937 \\
\hline Age & .143 & .210 & .035 & .642 \\
\hline Survey year & .138 & .070 & .050 & .871 \\
\hline Admission year & $.290^{*}$ & .000 & .134 & .634 \\
\hline Effort-reward imbalance & $.254^{*}$ & .001 & .279 & .778 \\
\hline Over-commitment & $.339^{*}$ & .000 & .094 & .728 \\
\hline Negative affect & $-.363^{*}$ & .000 & .412 & .705 \\
\hline $\mathrm{R}^{2}$ & .312 & & & \\
\hline Adjusted $\mathrm{R}^{2}$ & .255 & & & \\
\hline $\mathrm{F}$ & $5.444(\mathrm{p}=.000)$ & & \\
\hline
\end{tabular}

a) Transformed and standardized values in categorical regression 
Results of admission year and binary ERI were interpreted based on their beta coefficients and quantification results (Figure 1A, 1B). Because beta coefficient of admission year was positive (Figure 1A), higher scores on admission year variable were related to higher scores on engagement variable. That is, engagement increased in the order of 2013, 2015, 2014, 2012, 2016, 2017, and 2018 for admission year. The level of engagement was the highest for the 2018 admission cohort and the lowest for the 2013 admission cohort. Admission year accounted for $13.4 \%$ of the importance in this categorical regression model (Table 4 ).

As mentioned in Section 3. Statistical analysis, affiliation and year in school variables were highly correlated with admission year. Thus, these two variables were not included in our original categorical regression model. We inserted affiliation in another model and year in school in the other model instead of admission year and compared importance values of these three variables. We found that affiliation was not statistically significant. Its importance value was $2.3 \%$ in another model. Year in school was statistically significant (Beta $=.170, \mathrm{p}$ $=.005$ ). However, its importance value was $3.2 \%$ in the other model, which was about a quarter smaller than admission year's importance value in our original model.

As for binary ERI, its beta coefficient was positive (Figure 1B). Thus, the high score on binary ERI variable was related to higher scores for engagement variable. That is, when medical students felt that they were reciprocally rewarded for their efforts, their level of engagement was high. However, when they felt they were not reciprocally rewarded for their efforts, engagement was low. Binary ERI accounted for $27.9 \%$ of the importance in this categorical regression model (Table 4).

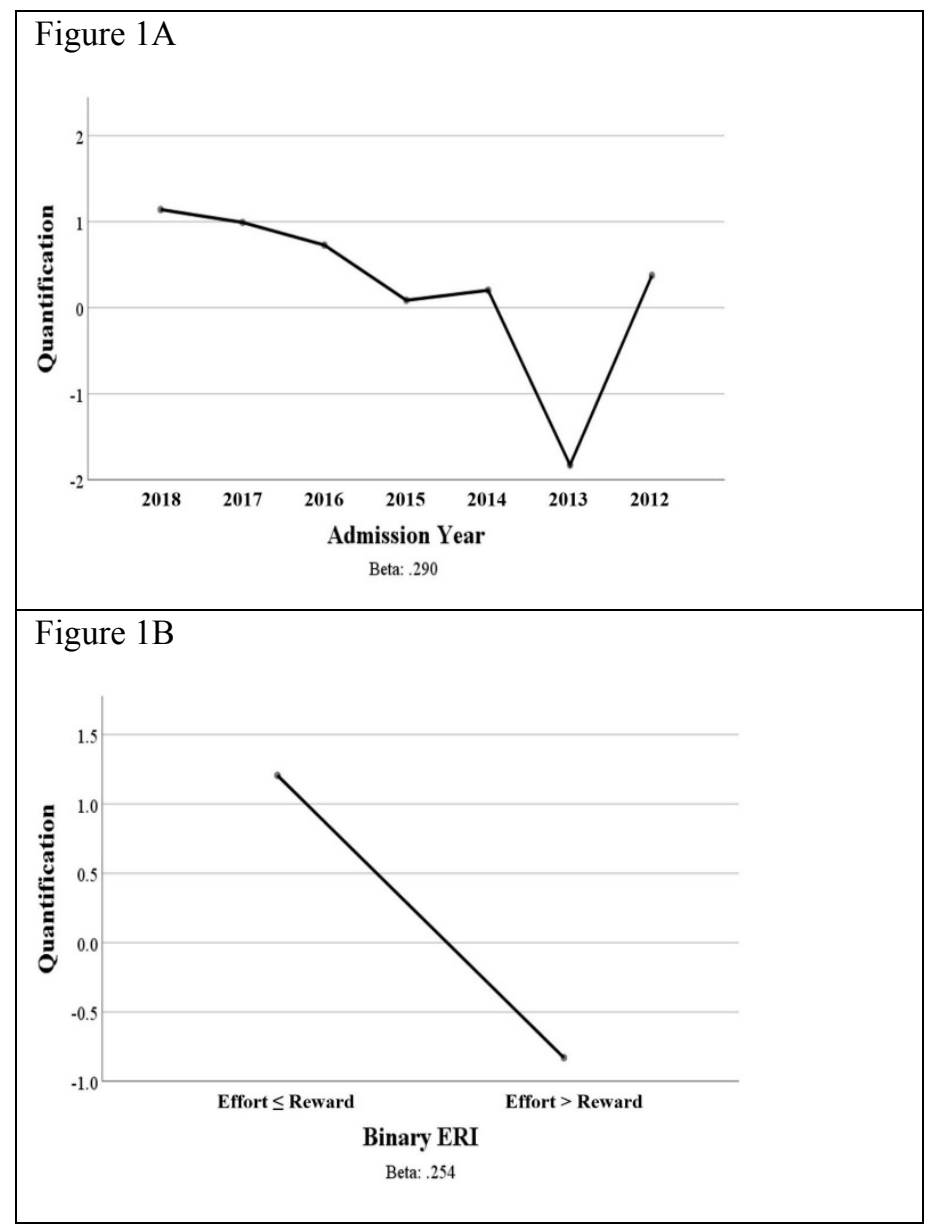

Figure 1. Transformation plots for (A) admission year and (B) binary ERI

\section{Discussion}

We tested whether academic engagement of premedical and medical students could be explained by admission year and ERI model. Hypotheses 1 and 2 were supported. Our results have the following implications. 


\subsection{Admission Year and Engagement}

First, admission year was the only significant factor among demographic variables including gender, age, and survey year in this research. Student cohort who entered in a certain year might have higher engagement than that in another year. This finding was consistent with previous studies (Gupta et al., 2013; Nishiyama et al., 2016) showing significant differences in psychological variables and academic performance by admission year. Professors sometimes have also noticed that different admission cohorts have different characteristics. However, this possible difference across admission years has not been much investigated so far. The result in this study implies that admission year can be a factor to consider when understanding engagement of medical students. In classes of our medical school, most students were learning together with those who entered in the same year. Thus, if engagement of a certain admission cohort is low, they can be encouraged to be more engaged in their studies.

Through this research, we did not know exactly why engagement differed by admission years. Since the curriculum of our medical school from 2012 to 2018 was the same, it could be assumed that characteristics of selected medical students were somewhat different due to changes in admission processes. This needs to be investigated in future studies. It could be argued that admission year might be interpreted as year in school because admission year and year in school had high correlation in our data. In fact, year in school was associated with engagement in other previous studies (Babenko et al., 2018; Liu et al., 2018). When we used year in school as an explanatory variable in the other categorical regression model instead of admission year, the importance value of admission year (13.4\%) was much larger than that of year in school (3.2\%) (Table 4). Therefore, we concluded that admission year would explain more variance of engagement than year in school, at least in our data.

\subsection{Effort-Reward Imbalance Model and Engagement}

Binary ERI was found to be associated with engagement in this study. In a view of positive psychology, this finding implies that keeping balance between effort and reward would be effective not only for reducing burnout and psychological problems (Hahn et al., 2017; Williams, Dziurawiec, \& Heritage, 2018), but also for increasing engagement (Hwang et al., 2019) of medical students. A review study on ERI model (Tsutsumi \& Kawakami, 2004) has emphasized the importance of being esteemed and supported by an organization. Rewards in our ERI questionnaire were about students' being acknowledged for their efforts and having good promotion prospects in the future. This is line with previous studies (Hahn et al., 2017; Richards et al., 2013) suggesting that medical schools need to promote a surrounding in which esteem is an obvious part of it and that positive self-esteem is a factor for increasing engagement of medical students. We believe that medical students' self-esteem could be facilitated by positive and constructive feedback (Richards et al., 2013) in social exchanges with supervisors and peers. Hence, professors and supervisors in classes and individual guidance are encouraged to acknowledge students' efforts expended and to connect students' participations and efforts with successful practices in their future job fields.

Unlike previous studies (Hahn et al., 2017; Hilger-Kolb et al., 2018) where medical students' OC was related to poor health, depression, and anxiety, higher OC was related to higher engagement in our premedical and medical students. In a competitive environment of medical schools (Wege, Muth, Li, \& Angerer, 2016), medical students who are usually characterized as high performers may not withdraw from their studies. Their over-commitment tendency might help them engage more in their studies. However, we think that this tendency needs to be regulated properly as it may lead to effort-reward imbalance in the long term (Feldt et al., 2016).

\subsection{Limitation}

This study has two limitations. First, admission years were figured out based on years in school that participants reported. Thus, admission years for a small number of returning students might have been calculated differently. Since the rate was very low each year, this study did not take that into account. The second limitation was that admission year was found to have high correlation with year in school. Further data collection year after year would be required to reduce the correlation between these two variables.

\section{Conclusion}

Vigorous, committed, and absorbed mental state in learning situations represents psychological well-being of medical students and may lead to high academic performance. Our study showed that engagement of medical student cohorts might be different according to admission year. Our results also reveal that if students feel they are esteemed and supported by an organization that they belong to, they will have more positive and fulfilling experiences with their studies. We hope these findings will help faculty to recognize that admission cohorts may exhibit different engagements and to intervene to increase their or individual student's engagement. 


\section{References}

Babenko, O., Mosewich, A., Abraham, J., \& Lai, H. (2018). Contributions of psychological needs, self-compassion, leisure-time exercise, and achievement goals to academic engagement and exhaustion of Canadian medical students. Journal of Educational Evaluation for Health Professions, 15, 2-16. https://doi.org/10.3352/jeehp.2018.15.2

Feldt, T., Hyvonen, K., Makikangas, A., Rantanen, J., Huhtala, M., \& Kinnunen, U. (2016). Overcommitment as a predictor of effort-reward imbalance: Evidence from an 8-year follow-up study. Scandinavian Journal of Work, Environment and Health, 42(4), 309-319. https://doi.org/10.5271/sjweh.3575

Feuerhahn, N., Kühnel, J., \& Kudielka, B. M. (2012). Interaction effects of effort-reward imbalance and overcommitment on emotional exhaustion and job performance. International Journal of Stress Management, 19(2), 105-131. https://doi.org/10.1037/a0028338

Gómez, P., Pérez, C., Parra, P., Ortiz, L., Matus, O., Mccoll, P., . . Meyer, A. (2015). Academic achievement, engagement and burnout among first year medical students. Revista Medica de Chile, 143, 930-937.

Gupta, N., Nagpal, G., \& Dhaliwal, U. (2013). Student performance during the medical course: Role of pre-admission eligibility and selection criteria. The National Medical Journal of India, 26(4), 223-226.

Hahn, H., Kropp, P., Kirschstein, T., Rucker, G., \& Muller-Hilke, B. (2017). Test anxiety in medical school is unrelated to academic performance but correlates with an effort/reward imbalance. Plos One, 12(2), e0171220. https://doi.org/10.1371/journal.pone.0171220

Hansen, G. V., D'Urso, M. V., \& Fracchia, L. N. (2016). Burnout-engagement and personality factors in medical students at a public university. Vertex (Buenos Aires, Argentina), 27(129), 325-331.

Hilger-Kolb, J., Diehl, K., Herr, R., \& Loerbroks, A. (2018). Effort-reward imbalance among students at German universities: Associations with self-rated health and mental health. International Archives of Occupational and Environmental Health, 91(8), 1011-1020. https://doi.org/10.1007/s00420-018-1342-3

Hwang, J. E., Kim, N. J., Kwon, N., \& Kim, S. Y. (2019). An effort-reward imbalance model to study engagement and burnout: A pilot study. Journal of Education and Development, 3(2). https://doi.org/10.20849/jed.v3i2.542

Kaistha, M., Raina, S. K., Bhardwaj, A. K., Chander, V., Kumar, D., \& Sharma, S. (2013). A screening for presence of psychological distress among undergraduate medical students of a medical college in rural north-west India. International Journal of Clinical Psychiatry, 1(1), 20-23. https://doi.org/10.5923/j.ijcp.20130101.03

Kim, D. H., Hwang, J., Kim, E. J., Yoon, H. B., Shin, J. S., \& Lee, S. (2014). How different are premedical freshmen who enter after introducing a multiple mini-interview in a medical school?. Korean Journal of Medical Education, 26(2), 87-98. https://doi.org/10.3946/kjme.2014.26.2.87

Kim, S. H., Lee, K., Hur, Y., \& Kim, J. H. (2013). How medical students perform academically by admission types?. Korean Journal of Medical Education, 25(3), 201-209. https://doi.org/10.3946/kjme.2013.25.3.201

Kraft, H. G., Lamina, C., Kluckner, T., Wild, C., \& Prodinger, W. M. (2013). Paradise lost or paradise regained? Changes in admission system affect academic performance and drop-out rates of medical students. Medical Teacher, 35(5), e1123-e1129. https://doi.org/10.3109/0142159X.2012.733835

Lee, H. H., Kim, E. J., \& Lee, M. K. (2003). A validation study of Korea positive and negative affect schedule: The PANAS Scales. Korean Journal of Clinical Psychology, 22(4), 935-946.

Liu, H., Yansane, A. I., Zhang, Y., Fu, H., Hong, N., \& Kalenderian, E. (2018). Burnout and study engagement among medical students at Sun Yat-sen university, China: A cross-sectional study. Medicine, 97(15), e0326. https://doi.org/10.1097/MD.0000000000010326

McCormick, K., Salcedo, J., Peck, J., \& Wheeler, A. (2017). SPSS statistics for data analysis and visualization. Indianapolis, IN: John Wiley \& Sons.

Nishiyama, M., Suzuki, E., Hashimoto, M., Takaoka, N., Inaba, M., Kumakura, M., . . Kamikawa, Y. (2016). Association of low sense of coherence with poor subjective well-being: A three-month cohort study of new medical students in Japan. Japanese Journal of Health and Human Ecology, 82(1), 20-29.

Preckel, D., Meinel, M., Kudielka, B. M., Haug, H. J., \& Fischer, J. E. (2007). Effort-reward-imbalance, overcommitment and self-reported health: Is it the interaction that matters?. Journal of Occupational and 
Organizational Psychology, 80(1), 91-107. https://doi.org/10.1348/096317905x80183

Richards, J., Sweet, L. P., \& Billett, S. (2013). Preparing medical students as agentic learners through enhancing student engagement in clinical education. Asia-Pacific Journal of Cooperative Education, 14(4), 251-263.

Roemer, J. (2016). The Korean Utrecht Work Engagement Scale - Student (UWES - S): A factor validation study. TPM: Testing, Psychometrics, Methodology in Applied Psychology, 23(1), 65-81.

Schaufeli, W. B., Martinez, I. M., Pinto, A. M., Salanova, M., \& Baker, A. B. (2002). Burnout and engagement in university students: A cross-national study. Journal of Cross-Cultural Psychology, 33(5), 464-481.

Siegrist, J. (1996). Adverse health effects of high-effort/low-reward conditions. Journal of Occupational Health Psychology, 1(1), 27-41.

Siegrist, J., Starke, D., Chandola, T., Godin, I., Marmot, M., Niedhammer, I., \& Peter, R. (2004). The measurement of effort-reward imbalance at work: European comparisons. Social Science \& Medicine, 58(8), 1483-1499. https://doi.org/10.1016/s0277-9536(03)00351-4

Siegrist, J., Wege, N., Puhlhofer, F., \& Wahrendorf, M. (2009). A short generic measure of work stress in the era of globalization: Effort-reward imbalance. International Archives of Occupational and Environmental Health, 82(8), 1005-1013. https://doi.org/10.1007/s00420-008-0384-3

Singh, K., Junnarkar, M., \& Kaur, J. (2016). Measures of positive psychology: Development and validation. New Delhi: Springer.

Siyami, F., Akbari, B. M., \& Ayati, M. (2014). The role of students' gender and preferred teaching style in predicting student academic engagement in mashhad university of medical sciences. Iranian Journal of Medical Education, 14(9), 817-826.

Tsutsumi, A., \& Kawakami, N. (2004). A review of empirical studies on the model of effort-reward imbalance at work: Reducing occupational stress by implementing a new theory. Social Science \& Medicine, 59(11), 2335-2359. https://doi.org/10.1016/j.socscimed.2004.03.030

Watson, D., Clark, L. A., \& Tellegen, A. (1988). Development and validation of brief measures of positive and negative affect: The PANAS scales. Journal of Personality and Social Psychology, 54(6), 1063-1070.

Wege, N., Li, J., Muth, T., Angerer, P., \& Siegrist, J. (2017). Student ERI: Psychometric properties of a new brief measure of effort-reward imbalance among university students. Journal of Psychosomatic Research, 94, 64-67. https://doi.org/10.1016/j.jpsychores.2017.01.008

Wege, N., Muth, T., Li, J., \& Angerer, P. (2016). Mental health among currently enrolled medical students in Germany. Public Health, 132, 92-100. https://doi.org/10.1016/j.puhe.2015.12.014

Williams, C. J., Dziurawiec, S., \& Heritage, B. (2018). More pain than gain: Effort-reward imbalance, burnout, and withdrawal intentions within a university student population. Journal of Educational Psychology, 110(3), 378-394. https://doi.org/10.1037/edu0000212

\section{Copyrights}

Copyright for this article is retained by the author(s), with first publication rights granted to the journal.

This is an open-access article distributed under the terms and conditions of the Creative Commons Attribution license (http://creativecommons.org/licenses/by/4.0/). 